\title{
Maternal alcohol use and children's emotional and cognitive outcomes in rural South Africa
}

\author{
T J Rochat, ${ }^{1,2} \mathrm{PhD}$; B Houle,${ }^{3,4,5} \mathrm{PhD}$; A Stein, ${ }^{4,6}$ FRCPsych; J Mitchell, ${ }^{7}$ MA; R M Bland ${ }^{8,9,10}$ MD \\ ${ }^{1}$ Africa Health Research Institute, Durban, South Africa \\ ${ }^{2}$ MRC/Wits Developmental Pathways to Health Research Unit, School of Clinical Medicine, Faculty of Health Sciences, University of the \\ Witwatersrand, Johannesburg, South Africa \\ ${ }^{3}$ School of Demography, The Australian National University, Canberra, Australia \\ ${ }^{4}$ MRC/Wits Rural Public Health and Health Transitions Research Unit (Agincourt), School of Public Health, Faculty of Health Sciences, \\ University of the Witwatersrand, Johannesburg, South Africa \\ ${ }^{5}$ CU Population Center, Institute of Behavioral Science, University of Colorado at Boulder, Boulder, Colo., USA \\ ${ }^{6}$ Department of Psychiatry, University of Oxford, UK \\ ${ }^{7}$ Department of Psychology, Faculty of Humanities, University of Cape Town, South Africa \\ ${ }^{8}$ School of Public Health, Faculty of Health Sciences, University of the Witwatersrand, Johannesburg, South Africa \\ ${ }^{9}$ Royal Hospital for Sick Children, Glasgow, Scotland, UK \\ ${ }^{10}$ Institute of Health and Wellbeing, University of Glasgow, UK
}

Corresponding author: T J Rochat (tamsen.rochat@wits.ac.za)

Background. Alcohol use in South Africa (SA) is increasing. The World Health Organization (WHO) states that SA is the third-largest drinking population in Africa, with the highest rate of fetal alcohol syndrome in the world. Internationally, parental drinking during childhood is a risk factor for poor child mental health, behavioural problems and weaker educational outcomes in middle childhood. However, parental alcohol use in Africa is under-researched, and much of the literature on maternal alcohol consumption is restricted to clinical and pregnancy samples.

Objectives. To investigate alcohol use and hazardous drinking (HD) among mothers/primary caregivers of children aged 7 - 11 years in a rural SA cohort. We explored risk factors for drinking and the association between HD and child behaviour/cognition.

Methods. The primary outcome measure was the WHO Alcohol Use Disorder Identification Test (AUDIT) using the standardised cutoff for HD ( $\geq 8)$. Secondary measures were the Patient Health Questionnaire Depression Scale (PHQ-9), Patient Health Questionnaire General Anxiety Disorder Scale (GAD-7), Parenting Stress Index, short form (PSI-36), Child Behaviour Checklist (CBCL, parent reported), Kaufman Developmental Assessment Battery (KABC-II) for child cognition, and Neuropsychological Assessment Battery, 2nd edition, subtests (NEPSY-II) for executive function. We compared characteristics of those drinking/not drinking, using $\chi^{2}$ tests, and modelled outcomes on parenting stress, cognitive outcomes and CBCL scores for children using logistic regression analysis. We grouped mothers/ caregivers engaged in HD to examine its effect on parent/child outcomes using $t$-tests to test for significant differences.

Results. Of 1505 women (1 266 mothers and 239 caregivers) with 1536 children, 12\% reported consuming alcohol and 3\% reported HD. Higher maternal/caregiver age ( 31 - 40 years, adjusted odds ratio (aOR) 0.57 (95\% confidence interval (CI) $0.4-0.9)$; $\geq 41$ years, aOR 0.30 (95\% CI 0.2 - 0.5)), education (matriculation, aOR 0.49 (95\% CI 0.3 - 0.9); post matriculation, aOR 0.30 (95\% CI 0.1 - 0.6)), and a stable relationship with the father (aOR $0.6(95 \%$ CI $0.4-1.0)$ ) were associated with no alcohol use. Food insecurity increased the odds of alcohol use (aOR 1.52 (95\% CI $1.1-2.1)$ ), while parental mental health (parenting stress, anxiety) and child mental health problems were associated with approximately double the odds of consuming alcohol in univariate analysis. Children of HD mothers/caregivers had higher mean scores for psychological problems (CBCL total score: no HD (mean 45.0) v. HD (mean 48.9); $p=0.029$ ) and lower cognitive scores (KABC Learning Scale: no HD (mean 14.3) v. HD (mean 12.8); $p=0.017$ ).

Conclusions. While HD rates were low, maternal/caregiver alcohol use negatively impacted on parenting and children's behavioural/ cognitive outcomes. International evidence suggests that integrated approaches engaging parents and families may be more effective for parent-child outcomes than individual psychiatric or medical care for the parent on their own.

S Afr Med J 2019;109(6):526-534. DOI:10.7196/SAMJ.2019.v109i6.13120

Alcohol use in South Africa (SA) has shown an upward trend, with a 2008 population-based study ( $N=13828)$ reporting drinking among $41.5 \%$ of men and $17.1 \%$ of women. ${ }^{[1,2]}$ Rates of binge drinking (17.1\% of men and $3.8 \%$ of women) and hazardous drinking (HD) (17\% of men and $2.9 \%$ of women) also showed increases. ${ }^{[1]}$ While these rates are lower than those in some other developing countries, ${ }^{[3]}$ a 2014 World Health Organization (WHO) report ${ }^{[4]}$ that examined alcohol use in 194 countries found SA to be the third-largest drinking population in Africa, with high rates of drinking among pregnant women and the highest rate of fetal alcohol syndrome (FAS) in the world. This pattern of drinking has considerable potential for causing ill-health or social harm, ${ }^{[5]}$ and is therefore an important public health issue. While a higher proportion of men than women in the general population of SA report drinking, the rate of drinking among pregnant women in SA is also reported to be high, ranging from $34 \%$ to $51 \%{ }^{[6]}$ compared with rates of $20-32 \%$ in the USA, UK and 
Canada. ${ }^{[7]}$ Studies in SA have shown that the majority of drinking during pregnancy is binge drinking. ${ }^{[8,9]}$ This pattern of drinking, and the well-established adverse effects of alcohol use on prenatal development, have resulted in a large body of evidence examining drinking among pregnant SA women. Recent prevalence rates of FAS have been reported as ranging from 68.0 to 89.2 per $1000(N=818)$ among grade 1 pupils in Western Cape Province and as 67.2 per 1000 in Northern Cape Province $(N=1835),{ }^{[10,11]}$ compared with an average estimate of 0.97 per 1000 in resource-rich settings. ${ }^{[12]}$ Current research is limited, as many of the studies were conducted in the Western and Northern Cape, both known to have significantly higher alcohol consumption rates compared with the rest of SA. ${ }^{[1]}$ One study set in KwaZulu-Natal (KZN) Province ${ }^{[8]}$ examined alcohol consumption among HIV-infected pregnant women attending antenatal clinics. A drinking rate of $18 \%$ was reported among the sample of 1201 women; however, in this group 67\% engaged in binge drinking.

It is likely that without intervention, drinking problems during pregnancy and around the time of childbirth will continue to impact on parenting care throughout childhood. There is increasing evidence that parental drinking during childhood negatively affects parenting ${ }^{[13]}$ and is a risk factor for poor child mental health, behavioural problems and weaker educational outcomes in middle childhood. ${ }^{[14]}$ Furthermore, research suggests that if a mother drinks, it is likely that there are other problem drinkers in the household. ${ }^{[15]}$ Parental drinking frequently occurs together with other negative childhood experiences, ${ }^{[16]}$ and children exposed to it have an increased likelihood of later drinking problems themselves. ${ }^{[17]}$ The majority of research in this field is international, and to our knowledge there is only one study in SA that has linked current maternal drinking to childhood behavioural and/or developmental disorders. In this research, which examined a small sample in Cape Town $(N=110)$, mothers who drank were much more likely to have a child with behavioural or developmental disorders (3 times more likely if drinking 3 times per week; 4.5 times more likely for binge drinkers) than mothers who did not drink. ${ }^{[18]}$ Parental drinking is likely to be equally problematic for parenting and child outcomes in African contexts more widely, and while drinking during the antenatal and postnatal periods appears to be common, much of the literature on alcohol consumption from African settings has been restricted to pregnancy, specific geographical areas, and clinical samples.

\section{Objectives}

The extent and impact of alcohol consumption among parents in population studies is under-researched. To address this gap, we investigated alcohol use and $\mathrm{HD}$ among mothers and primary caregivers of children aged 7 - 11 years, in a large rural SA cohort. We focused on maternal and/or primary caregiver drinking, as most children in southern Africa are in the primary care of their biological mothers. The objectives of this study were to examine: $(i)$ the extent of alcohol use and HD in mothers and primary caregivers; (ii) risk factors associated with alcohol use and HD in this group; and (iii) whether HD was associated with problems in child behaviour and poorer cognition.

\section{Methods}

As part of a cohort study, the Siyakhula cohort, ${ }^{[19,20]}$ we enrolled 1536 HIV-uninfected children, aged 7 - 11 years. Inclusion criteria were mothers to be alive and resident in the study area, children to be HIVuninfected and aged 7 - 11 years, and mothers and children to have known HIV status. Mothers gave written consent, children assented, and if a primary caregiver other than the mother was identified, consent was obtained and their data collected. The Biomedical Research Ethics Committee of the University of KwaZulu-Natal approved the study (ref. no. BF184/12).

The Siyakhula cohort has been described in detail. ${ }^{[20]}$ In brief, it was established in 2012 in rural KZN as part of the Canadian Grand Challenges 'Saving Brains' initiative to support the re-enrolment of cohorts to examine the developmental outcomes of children and associations with early-life factors. ${ }^{[19]}$ Children in the Siyakhula cohort are all HIV-negative and were born between 2001 and 2006, and include those born to HIV-positive and HIV-negative mothers (i.e. HIV-exposed and HIV-unexposed children, respectively). Some of the children had previously been part of an exclusive breastfeeding support intervention (the Vertical Transmission Study (VTS)), and others were similar-aged children from the then Africa Centre for Health and Population Studies (now called the Africa Health Research Institute (AHRI) Demographic Surveillance System (DSS)). Their HIV exposure at birth is known from clinical testing data in the VTS and from HIV surveillance data in the DSS. The cohort also includes data on HIV exposure in fetal and early life, and other factors known to impact on later developmental outcomes from these data sources. Children in Siyakhula had one assessment at primary school age (7 - 11 years) where data were collected on their growth, health, cognition, education and emotional-behavioural outcomes. ${ }^{[19,21]}$ Cognitive, mental health and parenting data were collected on their biological mother or primary caregiver. ${ }^{[22]}$ The HIV status of all enrolled women and children was known, and testing was offered to those who were unsure of their current status. We excluded children who were HIV-positive, as this cohort was established to examine developmental outcomes and associations with early-life factors, and these children have HIV-specific developmental risks. ${ }^{[22]}$

The primary outcome measure used for this secondary analysis was the WHO Alcohol Use Disorder Identification Test (AUDIT), considered a gold-standard measure and including 10 items on alcohol use in three domains (hazardous use, dependence and harmful use). ${ }^{[23]} \mathrm{A}$ total score of $\geq 8$ indicates hazardous and harmful alcohol use, termed HD, as well as possible alcohol dependence. Secondary measures included maternal mental health measures: the Patient Health Questionnaire Depression Scale (PHQ-9), ${ }^{[24]}$ the Patient Health Questionnaire General Anxiety Scale (GAD-7) ${ }^{[24]}$ and the Parenting Stress Index, short form (PSI-36). ${ }^{[25]}$ The parenting stress index includes three subscales that examine parental distress, parent-child relationship dysfunction and the extent to which the parent finds the child difficult to parent. Standardised scoring, cutoffs and clinical algorithms were used (Table 1, footnote). Mother/ caregiver clinical depression and anxiety were determined using the validated PHQ diagnostic algorithm as described in the footnote to Table 1 . To determine clinical parenting stress, we used the $\geq 90$ th percentile as a cut-off because there is no validated cut-off (beyond the widely used 50th percentile, which indicates elevated parenting stress) in the literature. Importantly, parenting stress scores were normally distributed. The measures used in this study have been widely used in this population ${ }^{[21,22,26,27]}$ and showed good reliability in this study (Cronbach alpha: AUDIT $\alpha=0.92$, PHQ- $9 \alpha=0.81$, GAD-7 $\alpha=0.81$, PSI $-36 \alpha=0.89$ ).

Children's emotional and behavioural problems were measured using the parent report version of the Child Behaviour Checklist (CBCL) for children aged 6-12 years (with permission and translation licence). ${ }^{[28]}$ The $\mathrm{CBCL}$ is a behavioural rating scale including 120 questions that a parent rates as 0 (not true as far as they know), 1 (somewhat or sometimes true) or 2 (very true or 
SAMJ RESEARGH

Table 1. Descriptive statistics of children and mothers by any alcohol use in the past year

\begin{tabular}{|c|c|c|c|c|}
\hline & No alcohol use (N=1 279), $n(\%)$ & Any alcohol use $(N=226), n(\%)$ & $p$-value & Total $(N=1505), n(\%)$ \\
\hline Maternal/caregiver age (years) & & & $<0.001^{*}$ & \\
\hline$\leq 30$ & $273(21.6)$ & $84(38.2)$ & & $357(24.1)$ \\
\hline $31-40$ & $495(39.3)$ & $82(37.3)$ & & $577(39.0)$ \\
\hline$\geq 41$ & $493(39.1)$ & $54(24.5)$ & & $547(36.9)$ \\
\hline Missing & 18 & 6 & & 24 \\
\hline Maternal/caregiver education & & & 0.105 & \\
\hline None & $75(6.0)$ & $16(7.2)$ & & $91(6.1)$ \\
\hline Primary school & $437(34.7)$ & $81(36.3)$ & & $518(35.0)$ \\
\hline Matriculation & 427 (33.9) & $86(38.6)$ & & $513(34.6)$ \\
\hline Post matriculation & $320(25.4)$ & $40(17.9)$ & & $360(24.3)$ \\
\hline Missing & 20 & 3 & & 23 \\
\hline Current primary caregiver & & & 0.677 & \\
\hline Other non-maternal caregiver & $201(15.7)$ & $38(16.8)$ & & $239(15.9)$ \\
\hline Mother is primary caregiver & $1078(84.3)$ & $188(83.2)$ & & $1266(84.1)$ \\
\hline Mother relationship status & & & $<0.001^{*}$ & \\
\hline Single & $202(15.9)$ & $41(18.8)$ & & $243(16.4)$ \\
\hline With biological father & $606(47.8)$ & $70(32.1)$ & & $676(45.5)$ \\
\hline New partner & $460(36.3)$ & $107(49.1)$ & & $567(38.2)$ \\
\hline Mother HIV status & & & 0.003 & \\
\hline Negative & $674(52.8)$ & $93(41.2)$ & & $767(51.0)$ \\
\hline Positive in pregnancy & $385(30.1)$ & $79(35.0)$ & & $464(30.9)$ \\
\hline Positive post birth & $218(17.1)$ & $54(23.9)$ & & $272(18.1)$ \\
\hline Missing & 2 & 0 & & 2 \\
\hline Mother employed & & & 0.758 & \\
\hline No & $936(73.2)$ & $167(74.2)$ & & $1103(73.4)$ \\
\hline Yes & $342(26.8)$ & $58(25.8)$ & & $400(26.6)$ \\
\hline Missing & 1 & 1 & & 2 \\
\hline Household food insecurity & & & $<0.001^{*}$ & \\
\hline None & $680(53.5)$ & $89(40.3)$ & & $769(51.5)$ \\
\hline At least once in past 4 weeks & $591(46.5)$ & $132(59.7)$ & & $723(48.5)$ \\
\hline Missing & 8 & 5 & & 13 \\
\hline Household asset ownership & & & 0.479 & \\
\hline No fridge & $340(26.6)$ & $55(24.3)$ & & $395(26.2)$ \\
\hline Owns fridge & $939(73.4)$ & $171(75.7)$ & & $1110(73.8)$ \\
\hline Maternal/caregiver disorders & & & & \\
\hline Depression $^{\dagger}$ & & & 0.032 & \\
\hline Absent & $1212(94.8)$ & $206(91.2)$ & & $1418(94.2)$ \\
\hline Present & $67(5.2)$ & $20(8.8)$ & & $87(5.8)$ \\
\hline Anxiety ${ }^{*}$ & & & 0.022 & \\
\hline Absent & $1243(97.2)$ & $213(94.2)$ & & $1456(96.7)$ \\
\hline Present & $36(2.8)$ & $13(5.8)$ & & $49(3.3)$ \\
\hline Parenting stress ${ }^{\varsigma}$ & & & $0.002^{*}$ & \\
\hline Absent & $1167(91.2)$ & $191(84.5)$ & & $1358(90.2)$ \\
\hline Present & $112(8.8)$ & $35(15.5)$ & & $147(9.8)$ \\
\hline Child age (years) & & & 0.184 & \\
\hline $7-8$ & $188(14.7)$ & $41(18.1)$ & & $229(15.2)$ \\
\hline$\geq 9$ & $1091(85.3)$ & $185(81.9)$ & & $1276(84.8)$ \\
\hline Child gender & & & 0.375 & \\
\hline Girl & $731(57.2)$ & $122(54.0)$ & & $853(56.7)$ \\
\hline Boy & $548(42.8)$ & $104(46.0)$ & & $652(43.3)$ \\
\hline Child internalising problems & & & 0.014 & \\
\hline Below threshold & $1189(93.2)$ & $200(88.5)$ & & $1389(92.5)$ \\
\hline Above threshold & $87(6.8)$ & $26(11.5)$ & & $113(7.5)$ \\
\hline Missing & 3 & 0 & & 3 \\
\hline Child externalising problems & & & 0.006 & \\
\hline Below threshold & $1177(92.2)$ & $196(86.7)$ & & $1373(91.4)$ \\
\hline Above threshold & $99(7.8)$ & $30(13.3)$ & & $129(8.6)$ \\
\hline Missing & 3 & 0 & & 3 \\
\hline \multicolumn{5}{|c|}{ 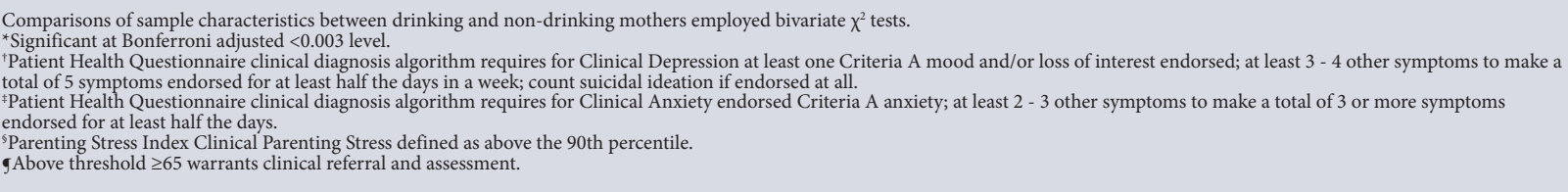 } \\
\hline
\end{tabular}


often true). These ratings make up a composite 'Total problems' score, a high score indicating more problems. CBCL scores were normed using multicultural Rating-to-Score norming software (purchased from ASEBA (the Achenbach System of Empirically Based Assessment), USA) to produce normed $t$-scores for the 'total' score and the internalising and externalising subscales, and for the six Diagnostic and Statistical Manual of Mental Disorders (DSM) disorders, including affective, anxiety and somatic disorders and attention deficit hyperactivity, oppositional and conduct disorders. Cronbach's reliability was high $(\alpha=0.94)$, exceeding the $\alpha=0.75$ recommendation for a stand-alone measure. ${ }^{[20]}$ For the $\mathrm{CBCL}$ internalising and externalising subscales, we used the threshold of $\geq 65$ on normed $t$-scores, as recommended by the test developers as the clinical risk cut-off and widely used in SA and southern Africa. ${ }^{[29]}$

Child cognition was measured using the Kaufman Assessment Battery for Children, 2nd edition (KABC-II), a validated measure of cognitive development in children aged $3-18$ years. ${ }^{[30]}$ The test battery was implemented using the Luria model theoretical approach, well suited to children in low-income, cross-cultural settings where quality of and exposure to school may vary. Eleven subtests were administered, including both verbal and non-verbal tests for all domains. Subtests were scored into four index scales, covering all aspects of cognition and used to calculate a mental processing index reflective of general intelligence. The KABC-II test battery is licensed to Pearson Ltd, USA, and test kits and forms were purchased. All subtests in the Luria model battery were retained, without adaptation, while the administration manual was translated under licence from Pearson Ltd, with fees waived. Three additional subtests to the KABC-II were added to test executive function capacities: working memory, inhibition and switching. These subtests were drawn from the Neuropsychological Assessment Battery, 2nd edition (NEPSYII), also licensed to Pearson Ltd, USA. ${ }^{[31]}$ Selective assessments used individual subtests in the NEPSY battery (attention and executive function domain) considered appropriate for focused evaluation of neuropsychological functioning. Test kits and forms were purchased; tests were used in their original format, while auditory stimuli were translated under translation licence from Pearson, again with fees waived. Research assistants with 5 - 7 years of research experience administered the assessments. In this study the KABC showed good reliability $(\alpha=0.78)$ and the originally validated structure was maintained $\left(\chi^{2}=6.30, p=0.432\right) .{ }^{[32]}$

Data were collected over three visits on separate days. Mothers were interviewed at home or at a central office, depending on what was most convenient. Children were assessed at a centralised assessment centre to ensure equivalence of assessment environment. Assessments lasted between 1 and 3 hours, and regular breaks and refreshments were provide to minimise measurement fatigue.

We defined two outcomes for our analyses: (i) drinking, if the respondent reported any drinking in the past year; and (ii) HD, if the respondent had a total AUDIT score of $\geq 8$. The cut-off for HD was that recommended by the WHO. It has been widely validated and is commonly used in both practice and large-scale research in SA (see for example Peltzer et al. $\left.{ }^{[1]}\right)$.

We began our analysis by examining bivariate differences in sample characteristics of mothers and children by comparing drinking and non-drinking mothers using $\chi^{2}$ tests. Next, we used logistic regression analysis to examine multivariate mother and child characteristics associated with any alcohol use. Covariates included mother/caregiver age and education; whether the mother was the primary caregiver; mother's relationship status, HIV status and employment; household food insecurity; ownership of fridge (as an indicator of household socioeconomic status); and child age and sex. Finally, we examined mother and child outcomes to explore the impact of HD, comparing mothers who engaged in HD with those who did not. We included outcomes on parenting stress, cognitive outcomes and CBCL scores for children and tested for significant differences between mothers who engaged in HD and those who did not, using $t$-tests.

\section{Results}

A total of 1506 participating mothers and caregivers completed the assessments. One mother had missing AUDIT data and was removed from analysis, leaving a final sample of 1 505: 1266 mothers and 239 primary caregivers (Fig. 1). The majority of the mothers/ caregivers were aged $31-40$ years $(39.0 \%)$, and most of the children $(84.8 \%)$ were aged $>9$ years (Table 1$)$. Mothers/caregivers were categorised as not drinking ( $n=1279,85.0 \%)$, drinking but below the HD threshold ( $n=181,12.0 \%$ ), and HD ( $\geq 8$ AUDIT) $(n=45,3.0 \%)$.

Of the 1505 women, 1428 (1 220 mothers and 208 primary caregivers) with complete data were included in the logistic regression analysis (Table 2): 432 (30.3\%) were HIV-positive during their pregnancy, $260(18.2 \%)$ became infected after delivery, and 736 (51.5\%) were HIV-negative. When examining children being cared for by their biological mothers ( $n=1220$ mothers with known HIV status), differences in maternal HIV status according to alcohol use or not were significant but small (13.6\% HIV-negative v. $18.2 \%$ HIV-positive mothers; $p=0.014$ ). Older maternal age, higher levels of education and being in a current relationship with the child's biological father were significantly associated with no alcohol use. Households where the mother reported food insecurity had significantly increased odds of any alcohol use. Being HIV-positive during pregnancy or becoming infected after delivery, and mental health problems in the child (CBCL internalising or externalising) or mother (anxiety or parenting stress), significantly increased the odds of drinking in univariate but not multivariate analyses. Of the 45 women reporting HD, most were mothers $(n=41)$ and not alternative primary caregivers $(n=4)$. Few had comorbid mental illness meeting clinical thresholds for depression $(n=6)$, or anxiety $(n=6)$; a further 3 met criteria for both depression and anxiety, while 12 had significant parenting stress.

When examining mean differences, parental distress, parent-child relationship dysfunction and difficult child scales on the parenting stress index were higher in the HD group (Table 3). Children of HD mothers/caregivers were significantly more likely to have lower scores on the KABC Learning Scale, and had significantly higher CBCL internalising and total CBCL scores.

\section{Discussion}

The majority of the sample was classified as not drinking, with $12 \%$ reporting drinking and $3 \%$ engaging in $\mathrm{HD}$. These overall rates are slightly lower than those reported among SA women in the general population; however, the rates of $\mathrm{HD}$ are similar. ${ }^{[1]}$ The lower rate may be related to the sample being predominantly rural, as in this setting cultural practices may discourage alcohol use among women, self-report may be lower given the stigma associated with alcohol use, and access to alcohol may be more difficult. ${ }^{[33,34]}$ Compared with no alcohol use (or alcohol use below a hazardous level), we found that being raised by a mother with HD was significantly associated with children's poorer emotional-behavioural and cognitive development. Children of HD mothers scored significantly lower than average on the learning scale of the KABC-II, which measures comprehension and capacity to learn efficiently, both important for educational 


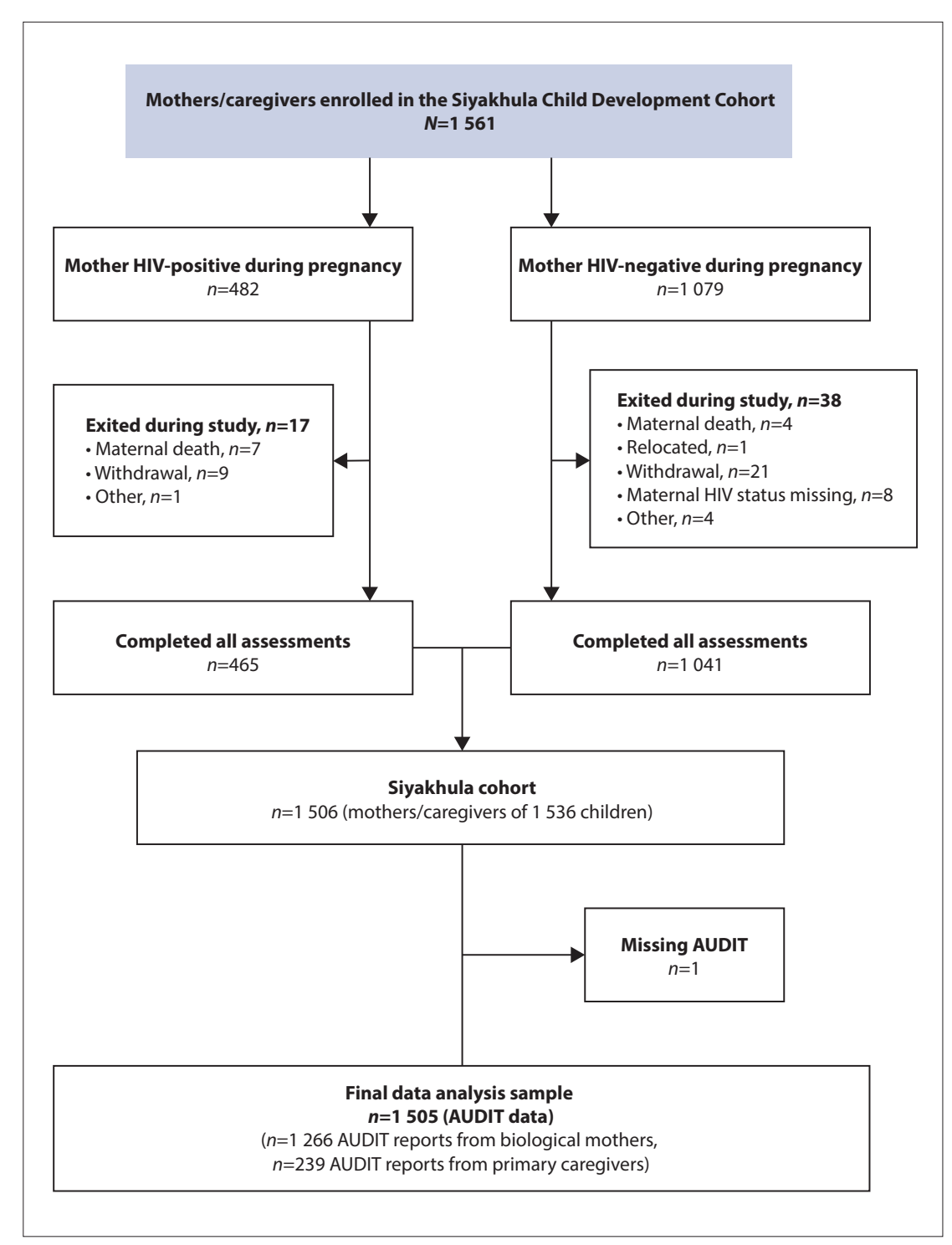

Fig. 1. Consort diagram of Siyakhula mothers, caregivers and children included in the data analysis.

success. Associations between parental alcohol abuse, poor scholastic achievement and emotional difficulties in children are well established in the international literature, ${ }^{[14,16]}$ and are also supported by evidence from SA literature on FAS. ${ }^{[10,35]}$

Our results show that exposure to a drinking parent increases the risk of a child having emotional, behavioural or developmental problems two-fold, which is comparable to research in a smaller sample of parents with children of a similar age in Cape Town. ${ }^{[18]}$ While the numbers are small, the effects appear substantial for children, showing the important negative impact that hazardous maternal alcohol use can have on the mental health and educational potential of children. Interventions are urgently needed for this high-risk group, but only a few have been tested in SA, almost exclusively for pregnant or postnatal women. breastfeeding), which may be less motivating for mothers of primary school age children, whose drinking may be perceived as having a less direct, or less important, effect. Equally, by $7-11$ years postnatally (as in this study), maternal drinking patterns may be more established and therefore more difficult to change.

To deal with barriers and challenges in the existing healthcare services in SA, the use of community healthcare workers (CHWs) has become increasingly popular. This approach was used in the Cape Town Philani Intervention Program $(N=549),{ }^{[37]}$ in which CHWs worked with antenatal and postnatal women to deliver a home-based intervention addressing issues including HIV, alcohol, nutrition, mental health and family healthcare. This intervention showed several significant improvements for mothers and infants, but there were no significant differences in the alcohol outcomes. The intervention shows potential for CHWs to provide education on alcohol use, and to screen for problematic drinking behaviours in the perinatal period. Interventions such as Philani may assist in ensuring that highrisk mothers and their children identified in routine $\mathrm{CHW}$ home visits are referred to appropriate services, although the validity of the Philani intervention has not been tested outside the perinatal period.

Importantly, recent systematic reviews and evidence from high-income settings have found that integrated approaches ${ }^{[38]}$ engaging parents and families in care are more effective for parent-child outcomes than individual psychiatric care. Improved parenting outcomes have been particularly associated with parenting improvements resulting from attachment-based parenting interventions, children residing in the treatment facility, and improvements in maternal mental health. ${ }^{[13]}$ Very few controlled studies have been published in this area. A systematic review ${ }^{[38]}$ of randomised controlled trials (RCTs) aimed at improving outcomes for children exposed to parental substance abuse highlighted two relevant interventions. The Parents under Pressure (PUP) programme targeted parental abuse of substances and/or alcohol, and was compared with a brief intervention and standard of care ( $N=64$ families). The PUP intervention involved weekly sessions at home for 3 4 months and the brief intervention two sessions by therapists at a clinic, while the standard of care had no parenting sessions other than routine substance abuse clinical care. The PUP intervention significantly improved family functioning and reduced 


\begin{tabular}{|c|c|c|c|c|c|c|}
\hline \multirow[b]{2}{*}{ Characteristics } & \multicolumn{3}{|c|}{ Univariate $(N=1428)$} & \multicolumn{3}{|c|}{ Multivariate $(N=1428)$} \\
\hline & OR & $95 \% \mathrm{CI}$ & $p$-value & aOR & $95 \% \mathrm{CI}$ & $p$-value \\
\hline \multicolumn{7}{|l|}{ Maternal/caregiver age (years) } \\
\hline$\leq 30$ & 1 & $1.0-1.0$ & & 1 & $1.0-1.0$ & \\
\hline $31-40$ & 0.58 & $0.4-0.8$ & $0.002^{*}$ & 0.57 & $0.4-0.9$ & $0.006^{*}$ \\
\hline$\geq 41$ & 0.37 & $0.3-0.5$ & $<0.001^{*}$ & 0.30 & $0.2-0.5$ & $<0.001^{*}$ \\
\hline \multicolumn{7}{|l|}{ Maternal/caregiver education } \\
\hline None & 1 & $1.0-1.0$ & & 1 & $1.0-1.0$ & \\
\hline Primary school & 0.82 & $0.5-1.5$ & 0.519 & 0.61 & $0.3-1.2$ & 0.131 \\
\hline Matriculation & 0.85 & $0.5-1.5$ & 0.599 & 0.49 & $0.3-0.9$ & $0.027^{\star}$ \\
\hline Post matriculation & 0.53 & $0.3-1.0$ & $0.052^{*}$ & 0.30 & $0.1-0.6$ & $0.001^{\star}$ \\
\hline \multicolumn{7}{|l|}{ Current primary caregiver } \\
\hline Other non-maternal caregiver & 1 & $1.0-1.0$ & & 1 & $1.0-1.0$ & \\
\hline Mother is primary caregiver & 0.91 & $0.6-1.4$ & 0.67 & 0.74 & $0.5-1.2$ & 0.213 \\
\hline \multicolumn{7}{|l|}{ Mother relationship status } \\
\hline Single & 1 & $1.0-1.0$ & & 1 & $1.0-1.0$ & \\
\hline With biological father & 0.58 & $0.4-0.9$ & $0.012^{\star}$ & 0.6 & $0.4-1.0$ & $0.030^{*}$ \\
\hline New partner & 1.14 & $0.8-1.7$ & 0.532 & 0.94 & $0.6-1.5$ & 0.784 \\
\hline \multicolumn{7}{|l|}{ Mother HIV status } \\
\hline Negative & 1 & $1.0-1.0$ & & 1 & $1.0-1.0$ & \\
\hline Positive in pregnancy & 1.39 & $1.0-2.0$ & $0.057^{*}$ & 1.09 & $0.7-1.6$ & 0.664 \\
\hline Positive post birth & 1.82 & $1.2-2.7$ & $0.002^{*}$ & 1.30 & $0.9-2.0$ & 0.206 \\
\hline \multicolumn{7}{|l|}{ Mother employed } \\
\hline No & 1 & $1.0-1.0$ & & 1 & $1.0-1.0$ & \\
\hline Yes & 0.93 & $0.7-1.3$ & 0.684 & 1.02 & $0.7-1.4$ & 0.932 \\
\hline \multicolumn{7}{|l|}{ Household food insecurity } \\
\hline None & 1 & $1.0-1.0$ & & 1 & $1.0-1.0$ & \\
\hline At least once in past 4 weeks & 1.66 & $1.2-2.2$ & $0.001^{*}$ & 1.52 & $1.1-2.1$ & $0.012^{*}$ \\
\hline \multicolumn{7}{|l|}{ Household asset ownership } \\
\hline No fridge & 1 & $1.0-1.0$ & & 1 & $1.0-1.0$ & \\
\hline Owns fridge & 1.05 & $0.8-1.5$ & 0.757 & 1.3 & $0.9-1.8$ & 0.155 \\
\hline \multicolumn{7}{|l|}{ Maternal/caregiver disorders } \\
\hline Depression $^{\dagger}$ & 1.5 & $0.8-2.6$ & 0.163 & 1.07 & $0.5-2.1$ & 0.848 \\
\hline Anxiety ${ }^{\ddagger}$ & 2.16 & $1.1-4.2$ & $0.025^{*}$ & 1.76 & $0.8-3.9$ & 0.159 \\
\hline Parenting stress & 1.77 & $1.2-2.7$ & $0.009^{*}$ & 1 & $0.6-1.7$ & 0.992 \\
\hline \multicolumn{7}{|l|}{ Child age (years) } \\
\hline $7-8$ & 1 & $1.0-1.0$ & & 1 & $1.0-1.0$ & \\
\hline$\geq 9$ & 0.69 & $0.5-1.0$ & 0.060 & 0.74 & $0.5-1.1$ & 0.164 \\
\hline \multicolumn{7}{|l|}{ Child gender } \\
\hline Girl & 1 & $1.0-1.0$ & & 1 & $1.0-1.0$ & \\
\hline Boy & 1.14 & $0.8-1.5$ & 0.400 & 1.11 & $0.8-1.5$ & 0.507 \\
\hline \multicolumn{7}{|l|}{ Child internalising problems ${ }^{\varsigma}$} \\
\hline Below threshold & 1 & $1.0-1.0$ & & 1 & $1.0-1.0$ & \\
\hline Above threshold & 1.72 & $1.1-2.8$ & $0.026^{*}$ & 1.06 & $0.6-1.9$ & 0.851 \\
\hline \multicolumn{7}{|l|}{ Child externalising problems } \\
\hline Below threshold & 1 & $1.0-1.0$ & & 1 & $1.0-1.0$ & \\
\hline Above threshold & 1.92 & $1.2-3.0$ & $0.004^{*}$ & 1.58 & $0.9-2.8$ & 0.107 \\
\hline \multicolumn{7}{|c|}{ 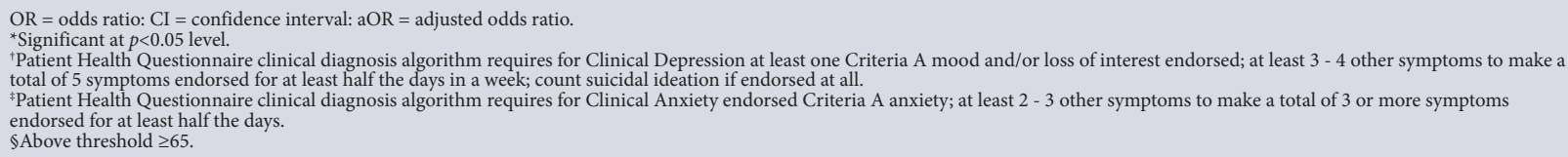 } \\
\hline
\end{tabular}

the risk of child abuse, while children in the PUP arm were reported to have fewer emotional and behavioural problems and more prosocial behaviours than those in either the brief intervention or standard-ofcare arms. ${ }^{[38]}$ In a three-arm trial $(N=135)$ of the Behavioural Couples
Therapy (BCT) intervention ${ }^{[38]}$ for men receiving outpatient treatment for alcohol and drug abuse, specifically targeting married or partnered men with children, participating men were randomly assigned to BCT, individual-based treatment (IBT) or couples-based psychoeducational 
Table 3. Caregiver parenting stress and child mental health, cognition, and executive function by HD and non-HD (no HD)

\begin{tabular}{|c|c|c|c|}
\hline & No HD, mean (SD) & HD, mean $(\mathrm{SD})$ & $p$-value \\
\hline \multicolumn{4}{|l|}{ Parenting stress } \\
\hline Parental distress scale & $27.4(11.0)$ & $32.1(11.4)$ & $0.005^{*}$ \\
\hline Parent-child dysfunction scale & $18.9(7.6)$ & $22.0(8.9)$ & $0.008^{\star}$ \\
\hline Difficult child scale & $23.2(8.0)$ & $27.1(10.3)$ & $0.001^{*}$ \\
\hline \multicolumn{4}{|l|}{ Child mental health } \\
\hline \multicolumn{4}{|l|}{ CBCL subscales } \\
\hline Total problems score & $45.0(11.6)$ & $48.9(15.3)$ & $0.029^{* *}$ \\
\hline Internalising problems & $47.7(9.9)$ & $51.9(12.7)$ & $0.005^{*}$ \\
\hline Externalising problems & $46.6(11.4)$ & $49.9(15.8)$ & 0.059 \\
\hline \multicolumn{4}{|l|}{$\mathrm{CBCL}_{\text {disorders }}^{\dagger}$} \\
\hline Affective & $0.05(0.22)$ & $0.13(0.34)$ & $0.017^{* *}$ \\
\hline Anxiety & $0.05(0.21)$ & $0.16(0.37)$ & $0.001^{*}$ \\
\hline Somatic & $0.10(0.30)$ & $0.16(0.37)$ & 0.220 \\
\hline ADHD & $0.04(0.21)$ & $0.09(0.29)$ & 0.153 \\
\hline Oppositional & $0.06(0.23)$ & $0.16(0.37)$ & $0.005^{\star}$ \\
\hline Conduct & $0.12(0.32)$ & $0.22(0.42)$ & $0.030^{* *}$ \\
\hline \multicolumn{4}{|l|}{ Child development } \\
\hline \multicolumn{4}{|l|}{ Cognition } \\
\hline Sequential & $16.7(4.5)$ & $17.3(5.6)$ & 0.407 \\
\hline Planning & $9.7(4.1)$ & $9.0(4.1)$ & 0.201 \\
\hline Learning & $14.3(4.1)$ & $12.8(4.0)$ & $0.017^{\star *}$ \\
\hline Simultaneous & $20.0(5.8)$ & $18.8(6.1)$ & 0.174 \\
\hline Riddles & $4.1(1.5)$ & $3.6(1.5)$ & $0.045^{* *}$ \\
\hline \multicolumn{4}{|l|}{ Executive function } \\
\hline Animal sorting & $15.1(3.1)$ & $14.4(3.3)$ & 0.091 \\
\hline Auditory attention & $6.7(3.3)$ & $6.0(3.1)$ & 0.191 \\
\hline Response set & $8.7(3.1)$ & $8.6(3.1)$ & 0.806 \\
\hline
\end{tabular}

attention control treatment (PACT). Participants in all the groups were expected to attend 32 treatment sessions. A difference between the approaches was that the IBT group attended all their treatment sessions by themselves, while the PACT group attended 20 individualbased sessions followed by 12 sessions that included their partner, although partners did not actively participate in the treatment sessions. BCT partners actively participated in the 12 BCT treatment sessions, which covered effective communication skills, positive behavioural exchanges between partners, and tools for eliminating verbal and physical aggression between partners. The results showed that children in the BCT group had significantly improved psychosocial scores at 6 and 12 months' follow-up compared with the IBT and PACT groups, although with relatively small effect sizes. A smaller second RCT of this intervention $(N=30)^{[38]}$ tested whether adding a parenting component to BCT would enhance the positive child outcomes found in the previous evaluation. An additional four parent training sessions were added to BCT, which included the men and their partners. While children who received the original BCT treatment showed improvements, these were not sustained over the 12-month follow-up; however, children in the families receiving the enhanced BCT, called Parent Skills with Behavioural Couples Therapy, showed greater improvements in problematic behaviour, depression and anxiety throughout the 12-month follow-up period than the children of the parents assigned to the other two groups. ${ }^{[38]}$

The literature also highlights risk factors associated with alcohol use prior to pregnancy, including being younger and single, smoking, and having a greater number of sexual partners. ${ }^{[39]}$ Given the exposure to these risk factors of young women of child-bearing age in many parts of SA, early interventions may have prevention potential. While healthcare settings are a good recruitment point to identify high-risk women, we are missing an opportunity to intervene and help women prior to or after pregnancy (as was the case in the present study) through home- and school-based interventions. A CHW approach has the potential to make an impact at a community level, and may need to expand to include all women of childbearing age, not just pregnant women and those in the immediate postpartum period. Early intervention and prevention are important, given our finding that maternal HD is strongly associated with poor outcomes in school-aged children.

Factors cited in the literature that protect mothers from alcohol abuse (older age, better education, stability of relationship) were also associated with no alcohol consumption in our research, ${ }^{[1,15]}$ while commonly reported risks, including food insecurity, were associated with alcohol use. ${ }^{[13,16]}$ Parental distress, experiencing parent-child dysfunction and parental report of a difficult child were also associated with HD. Screening to identify parents with HD habits in routine health and social welfare sectors may help to identify families at very high risk, which would in turn assist in directing limited resources to children and families in most need and who would benefit from more intense interventions. While parental depression, anxiety and parenting stress are frequently reported as co-morbid with alcohol use in the literature, ${ }^{[14,40,41]}$ we found that they were not 
significantly associated with HD in the multivariate model, although numbers of HDs were small and these findings should be interpreted with caution. However, it is possible that the mothers in this sample had specific problems with alcohol use that were not directly related to, or the consequence of, other mental health problems.

\section{Study limitations}

This study is limited by its observational design, and having one measurement point for alcohol use limits our ability to draw causal inferences. Longitudinal research is needed to disentangle these associations, to investigate the direction of effects and to assess whether these effects vary according to developmental age. There is some evidence that drinking around the time of childbirth may be linked to previous traumatic experiences, but we did not have a measure of trauma in our study. In addition, our measure of alcohol use relied on maternal self-report, and there is evidence that rates of HD are higher among women in urban than rural areas. It would therefore be important to replicate these findings in other settings. ${ }^{[1]}$ Future research in the form of prospective longitudinal studies with comparison group designs and larger samples of parents with children of all ages, rather than only pregnant and postnatal mothers, are needed in SA.

\section{Conclusions}

Although most literature in the field focuses on pregnancy-related drinking, maternal alcohol use at later stages of parenting has the potential to substantially negatively affect a child's behavioural and cognitive outcomes. Although they represent a relatively small group, families with HD mothers probably warrant a high level of care, even in resource-poor settings, to reduce morbidity and cost to society, particularly since HD has the potential to affect not only the mother but all children in the family. ${ }^{[14,16]}$ Maternal alcohol use is often under-reported, and where evidence of maternal drinking is found it is likely to reflect a broader picture of alcohol use and abuse among other adult family members. This situation can compound the effects of maternal HD on children, and presents an opportunity for family-centred services. Preventive work among groups of women of childbearing age may also be beneficial in preventing future HD. Further research is needed to test interventions in low-resource settings.

\section{Declaration. None.}

Acknowledgements. We thank the dedicated clinic, field and data teams; the KwaZulu-Natal Department of Health and staff at the local clinics and hospital for allowing us to work alongside them; and the infrastructure at the AHRI, previously the Africa Centre for Health and Population Studies. We are grateful to the study team, in particular Samu Dube, and thank Kobus Herbst, Dickman Gareta, Colin Newell and Ant Snyman for data management support, and the Community Liaison Office of the AHRI for their guidance throughout the study. We acknowledge Marie-Louise Newell as an investigator on the Siyakhula cohort, and acknowledge the collaborators on this grant: Hoosen Coovadia, Anna Coutsoudis, and Chris Desmond. We are grateful to Pearson Ltd for waiving the translation licence fee for the KABC and NEPSY assessment tools, and to Alan and Nadeen Kaufman for expert input on subtest selection and substitution, and translation.

Author contributions. TJR contributed to securing funding, study design and implementation of the research, participated in data analysis and interpretation, and drafted and critically revised the manuscript. BH led data analysis and interpretation, and critically revised the manuscript. AS contributed to securing funding and study design, participated in the interpretation of data, and critically revised the manuscript. JM participated in the interpretation of data and contributed to drafting and critically revising the manuscript. RMB contributed to securing funding, study design and implementation of the research, participated in interpretation of data, and critically revised the manuscript.

Funding. The AHRI, where the research took place, is funded by the Wellcome Trust (grant nos: previous Africa Centre for Population Health 097410/Z/11/Z, current AHRI 201433/Z/16/Z). The DSS is co-funded by the SA Department of Science and Technology (DST) through the DST/MRC South African Population Research Infrastructure Network (SAPRIN). The original Vertical Transmission Study was funded separately (Wellcome Trust 063009/Z/00/2). The re-enrolment and assessment of the cohort were funded by Grand Challenges Canada, Saving Brains (Grand Challenges 0063-03). TJR is supported by the Newton Advanced Fellowship Scheme (AF160108) and a Wellcome Trust Intermediate Fellowship in Public Health and Tropical Medicine (211374/Z/18/Z). The support of the DST-NRF Centre of Excellence in Human Development towards data analysis is also acknowledged (ACC2018004, OPP20160035 and OPP20150015).

Conflicts of interest. None.

1. Peltzer K, Davids A, Njuho P. Alcohol use and problem drinking in South Africa: Findings from a national population-based survey. Afr J Psychiatry 2011;14(1):30-37. https://doi.org/10.4314/ajpsy. v14i1.65466

2. Peltzer K, Ramlagan S. Alcohol use trends in South Africa. J Soc Sci 2009;18(1):1-12. https://doi.org/ 10.1080/09718923.2009.11892661

3. Guo W, Lanzi G, Luobu O, et al. An epidemiological survey of alcohol use disorders in a Tibetan 3. Guo W, Lanzi G, Luobu O, et al. An epidemiological survey of alcohol use disorders in a
population. Psychiatry Res 2008;159(1):56-66. https://doi.org/10.1016/j.psychres.2007.09.012

4. World Health Organization. Global status report on alcohol and health 2014. World Health Organization, 2014. https://apps.who.int/iris/bitstream/handle/10665/112736/9789240692763_eng. pdf;jsessionid=B3FAE9A34ABD6053CB61E1FC5823BFF2? sequence=1 (accessed 6 June 2019).

5. Obot IS. Alcohol use and related problems in sub-Saharan Africa. Afr J Drug Alcohol Stud 2006;5(1):17-26.

6. May PA, Gossage JP, Marais AS, et al. Maternal risk factors for fetal alcohol syndrome and partial fetal alcohol syndrome in South Africa: A third study. Alcohol Clin Exp Res 2008;32(5):738-753. https://doi. org/10.1111/j.1530-0277.2008.00634.x

7. Alvik A, Heyerdahl S, Haldorsen T, Lindemann R. Alcohol use before and during pregnancy: A population-based study. Acta Obstet Gynecol Scand 2006;85(11):1292-1298. https://doi. $\mathrm{org} / 10.1080 / 00016340600589958$

8. Desmond K, Milburn N, Richter L, et al. Alcohol consumption among HIV-positive pregnant women in KwaZulu-Natal, South Africa: Prevalence and correlates. Drug Alcohol Depend 2012;120(1):113-
in 118. https://doi.org/10.1016/.drugalcdep.2011.07.004

9. Rotheram-Borus MJ, le Roux IM, Tomlinson M, et al. Philani Plus (+): A mentor mother community Rotheram-Borus MJ, le Roux IM, Tomlinson M, et al. Philani Plus (+): A mentor mother community
health worker home visiting program to improve maternal and infants' outcomes. Prev Sci
2011;12(4):372-388. https://doi.org/10.1007/s11121-011-0238-1 2011;12(4):372-388. https://doi.org/10.1007/s11121-011-0238-1

10. May PA, Gossage JP, Marais AS, et al. The epidemiology of fetal alcohol syndrome and partial FAS in a South African community. Drug Alcohol Depend 2007;88(2-3):259-271. https://doi.org/10.1016/j. drugalcdep.2006.11.0077

11. Urban M, Chersich MF, Fourie L-A, Chetty C, Olivier L, Viljoen D. Fetal alcohol syndrome among grade 1 schoolchildren in Northern Cape Province: Prevalence and risk factors. S Afr Med J 2008;98(11):877-882. https://doi.org/10.1016/j.drugalcdep.2011.07.004

12. Abel EL, Sokol RJ. Incidence of fetal alcohol syndrome and economic impact of FAS-related anomalies. Drug Alcohol Depend 1987;19(1):51-70. https://doi.org/10.1016/0376-8716(87)90087-1

13. Niccols A, Milligan K, Sword W, Thabane L, Henderson J, Smith A. Integrated programs for mothers with substance abuse issues: A systematic review of studies reporting on parenting outcomes. Harm with substance abuse issues: A systematic review of studies
Reduct J 2012; $9: 14$. https://doi.org/10.1186/1477-7517-9-14

14. McLaughlin AE, Macdonald G, Livingstone N, McCann M. Interventions to build resilience in 4. McLaughlin AE, Macdonald G, Livingstone N, McCann M. Interventions to build resilience in
children of problem drinkers. Cochrane Database Syst Rev 2014, Issue 8. Art. No.: CD011237. https:// children of problem drinkers. Cochran
doi.org $/ 10.1002 / 14651858 . C D 011237$

15. Percy A, Thornton M, McCrystal P. The extent and nature of family alcohol and drug use: Findings from the Belfast youth development study. Child Abus Rev 2008;17(6):371-386. https://doi. org/10.1002/car.1046

16. Anda RF, Whitfield CL, Felitti VJ, et al. Adverse childhood experiences, alcoholic parents, and later risk of alcoholism and depression. Psychiatr Serv 2002;53(8):1001-1009. https://doi.org/10.1176/appi. ps.53.8.1001

17. Rossow I, Keating P, Felix L, McCambridge J. Does parental drinking influence children's drinking? A systematic review of prospective cohort studies. Addiction 2016;111(2):204-217. https://doi, org/10.1111/add.13097

18. Katwan E, Adnams C, London L. Childhood behavioural and developmental disorders. S Afr Med J 2011;101(10):724-727.

19. Rochat TJ, Houle B, Stein A, et al. Exclusive breastfeeding and cognition, executive function, and behavioural disorders in primary school-aged children in rural South Africa: A cohort analysis. PLoS Med 2016;13(6):e1002044. https://doi.org/10.1371/journal.pmed.1002044

20. Rochat T, Houle B, Stein A, Pearson R, Newell M, Bland R. Cohort profile: The Siyakhula cohort, rural South Africa. Int J Epidemiol 2017;46(6):1755-6n. https://doi.org/10.1093/ije/dyy009 
21. Rochat TJ, Houle B, Stein A, Pearson RM, Bland RM. Prevalence and risk factors for child mental disorders in a population-based cohort of HIV-exposed and unexposed African children aged 7 disorders in a population-based cohort of HIV-exposed and unexposed African children aged 7
11 years. Eur Child Adolesc Psychiatry 2018;27(12):1-14. https://doi.org/10.1007/s00787-018-1146-8

22. Rochat TJ, Houle B, Stein A, Pearson RM, Newell ML, Bland RM. Psychological morbidity and parenting stress in mothers of primary school children by timing of acquisition of HIV infection: A longitudinal cohort study in rural South Africa. J Dev Orig Health Dis 2018;9(1):41-57. https://doi.org/10.1017/ S204017441700068X

23. Reinert DF, Allen JP. The Alcohol Use Disorders Identification Test (AUDIT): A review of recent research. Alcohol Clin Exp Res 2002;26(2):272-279. https://doi.org/10.1111/j.1530-0277.2002.tb02534.x

24. Kroenke K, Spitzer RL, Williams JB, Lowe B. The Patient Health Questionnaire somatic, anxiety, and depressive symptom scales: A systematic review. Gen Hosp Psychiatry 2010:32(4):345-359. https//doi.

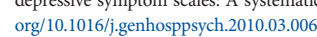

25. Abidin R. Parenting Stress Index Third Edition: Professional Manual. Lutz, Fla: Psychological Assessment Resources Inc., 1995.
Reidin R. Parenting Stest

26. Rochat TJ, Stein A, Cortina-Borja M, Tanser F, Bland RM. The Amagugu intervention for disclosure of maternal HIV to uninfected primary school-aged children in South Africa: A randomised controlled trial. Lancet HIV 2017;4(12):e566-e576. https://doi.org/10.1016/S2352-3018(17)30133-9

27. Rochat TJ, Arteche AX, Stein A, Mitchell J, Bland RM. Maternal and child psychological outcomes of HIV disclosure to young children in rural South Africa: The Amagugu intervention. AIDS 2015;29(Suppl 1):S67-S79. https://doi.org/10.1097/QAD.0000000000000668

28. Achenbach TM, Rescorla LA. Multicultural Supplement to the Manual for the ASEBA School-age Forms \& Profiles. Burlington, Vt: Research Center for Children, Youth, \& Families, University of Vermont, 2007.

29. Achenbach T, Rescorla L. Manual for the ASEBA School-age Forms \& Profiles. Burlington, Vt: Research Centre for Children, Youth and Families, University of Vermont, 2001.

30. Kaufman AS, Kaufman NL. KABC-II Kaufman Assessment Battery for Children. Bloomington, Ind: Pearson, 2004.

31. Brooks BL, Sherman EM, Strauss E. NEPSY-II: A developmental neuropsychological assessment. Child Neuropsychol 2009;16(1):80-101. https://doi.org/10.1080/09297040903146966

32. Mitchell JM, Tomlinson M, Bland RM, Houle B, Stein A, Rochat TJ. Confirmatory factor analysis of the Kaufman assessment battery in a sample of primary school-aged children in rural South Africa. S Afr I Psychol 2017;48(4):434-452. https://doi.org/10.1177/0081246317741822
33. Tanser F, Hosegood V, Bärnighausen T, et al. Cohort profile: Africa Centre Demographic Information System (ACDIS) and population-based HIV survey. Int J Epidemiol 2007;37(5):956-962. https://doi. org $/ 10.1093 / \mathrm{ije} / \mathrm{dym} 211$

34. Martinez P, Røislien J, Naidoo N, Clausen T. Alcohol abstinence and drinking among African women: Data from the World Health Surveys. BMC Public Health 2011;11(1):160. https://doi. org/10.1186/1471-2458-11-160

35. May PA, Gossage JP, Kalberg WO, et al. Prevalence and epidemiologic characteristics of FASD from various research methods with an emphasis on recent in-school studies. Dev Disabil Res Rev 2009;15(3):176-192. https://doi.org/10.1002/ddrr.688

36. May PA, Marais A-S, Gossage JP, et al. Case management reduces drinking during pregnancy among high risk women. Int J Alcohol Drug Res 2013;2(3):61-70. https://doi.org/10.7895/ijadr.v2i3.79

37. Le Roux IM, Tomlinson M, Harwood JM, et al. Outcomes of home visits for pregnant mothers and their infants: A cluster randomised controlled trial. AIDS 2013;27(9):1461-1471. https://doi. org/10.1097/QAD.0b013e3283601b53

38. Calhoun S, Conner E, Miller M, Messina N. Improving the outcomes of children affected by parental substance abuse: A review of randomized controlled trials. Subst Abuse Rehabil 2015;6:15-24. https:/ doi.org/10.2147/SAR.S46439

39. O'Connor MJ, Tomlinson M, LeRoux IM, Stewart J, Greco E, Rotheram-Borus MI. Predictors of alcohol use prior to pregnancy recognition among township women in Cape Town, South Africa. Soc Sci Med 2011;72(1):83-90. https://doi.org/10.1016/i.socscimed.2010.09.049

40. Kranzler HR, Rosenthal RN. Dual diagnosis: Alcoholism and co-morbid psychiatric disorders. Am J Addict 2003;12(s1):s26-s40. https://doi.org/10.1111/j.1521-0391.2003.tb00494.x

41. Vythilingum B, Roos A, Faure SC, Geerts L, Stein DJ. Risk factors for substance use in pregnant women in South Africa. S Afr Med J 2012;102(11):853-854. https://doi.org/10.7196/SAMJ.5019

Accepted 3 December 2018 